\title{
Comparative vibrational spectroscopic studies of 7-chloro-4- hydroxy-3-quinolinecarboxylic acid based on density functional theory
}

\author{
Sudesh Kumar Sharma, Yogesh Kumar Sharma, Ritu Saran, \\ Manoj Kumar Singh, B S Yadav
}

Molecular Spectroscopy and Biophysics Lab D N College, Meerut (U P) 250002

\begin{abstract}
The experimental and theoretical vibrational spectra (FT-IR and FT-Raman) of 7-chloro-4-hydroxy3-quinolinecarboxylic acid (7C4H3QCA) are investigated. The experimental FT-IR $\left(400-4400 \mathrm{~cm}^{-1}\right)$ and FTRaman spectra $\left(100-3500 \mathrm{~cm}^{-1}\right)$ spectra of the molecule are recorded. In the whole study the $C_{S}$ point group symmetry has been used. Theoretical Vibrational frequencies and geometric parameters (bond lengths and bond angles) were calculated using ab initio Hartree Fock (HF) and density functional B3LYP method with 6-31+G $(d, p)$ basis set. The complete vibrational assignments of wave numbers were made on the basis of potential energy distribution. The scaled B3LYP/6-3I+G $(d, p)$ results show the best agreement with the experimental values over the other methods.
\end{abstract}

Keywords: Vibrational spectroscopic investigation; $a b$ initio and DFT; 7-chloro-4-hydroxy-3quinolinecarboxylic acid

\section{Introduction}

Quinoline derivatives are widely used as a parent compound to make drugs (cancer [1], especially antimalarial medicines), fungicides, biocides, alkaloids, rubber chemicals, flavoring agents [2], catalyst, corrosion inhibitor, preservative, solvent for resins and terpenes. Malaria is a serious health problem, particularly in tropical regions. It is been estimated that there are between 300 and 500 million clinical cases of Malaria annually, leading to 1.1-2.7 million deaths [3]. During the erythrocytic stage of its life cycle, the Malaria parasite ingests and degrades $60-80 \%$ of host cell hemoglobin as a source of amino acids [4-6]. There is considerable evidence indicating that quinoline-based antimalarial agents such as chloroquine acts by forming toxic complexes with free hematin [7,8]. In a study by De et al., 7-chloroquinolines with $\mathrm{N}, \mathrm{N}$ 'diethyldiaminoalkane side chains with lengths between 2 and 12 carbons were found to be as effective as chloroquine against chloroquine-sensitive strains [9]. Recently, 4-aminoquinolines with different substituents at the 7-position and N-oxides quinolines were studied by De Dios et al. to examine drug-heme association constants $[10,11]$. A correlation was found for quinoline derivatives and their pharmaceutical behavior by ab initio calculated nuclear quadrupole resonance parameters of quinoline nitrogen [12]. Recent spectroscopic studies of the quinoline and their derivatives have been motivated because the vibrational electronic absorption spectra are very useful for the understanding of the specific biological process and in the analysis of relatively complex systems. In the present study, we extend a probing into the application of the HF/6-31+G (d, p) and B3LYP/6-31+G (d, p) basis set based on SQM method for vibrational spectra. The geometrical parameters of the most optimized geometry obtained via energy calculations were used for the DFT calculations. The infrared and Raman intensities were also predicted. Based on these calculations, the simulated FT-IR and FT-Raman spectra were obtained. The observed and the simulated spectra agree well. The theoretical HF and density functional theory analysis give information regarding the nature of structure, the functional groups and orbital interactions and mixing of skeletal frequencies. The introduction of one or more substituent in quinoline ring leads to the variation of charge distribution in the molecule, and consequently, this greatly affects the structural, electronic and Vibrational parameters. Though there are few studies on quinoline compounds [13-27], the structural characteristics and vibrational spectroscopic analysis of 7-chloro-4-hydroxy-3-quinolinecarboxylic acid by the quantum mechanical HF and DFT methods have not been studied. Thus, considering the industrial and biological importance of 7-chloro-4-hydroxy-3-quinolinecarboxylic acid, an extensive experimental and theoretical study on 7C4H3QCA to obtain a complete reliable and accurate vibrational, electronic transitions assignments and structural characteristics of the compound has been made.

The density functional theory (DFT) is a popular post-HF approach for the calculation of molecular structures, Vibrational frequencies and energies of molecules $[28,29]$. The DFT calculations with the hybrid exchange-correlation functional B3LYP [Becke's three parameter (B3) exchange in conjunction with the Lee- 
Yang-Parr's (LYP) correlation functional] which are especially important in systems containing extensive electron conjugation and electron lone pairs [30-35].

\section{Experimental Procedure}

The compound 7-chloro-4-hydroxy-3-quinolinecarboxylic acid (7C4H3QCA) in the solid form was purchased from the Sigma-Aldrich Chemical Company (Bangalore) with a stated purity of greater than 97\%, and it was used as such without further purification to record FT-IR and FT-Raman spectra. The FT-IR spectrum has been recorded by $\mathrm{KBr}$ pellet technique in the region between $4400-400 \mathrm{~cm}^{-1}$ using Perkin Elmer RX-1 (Spectra 2000) FT-IR Spectrometer. The frequencies for all sharp bands are accurate to $\pm 1 \mathrm{~cm}^{-1}$. The FTRaman spectrum was also recorded in the range between $3500-100 \mathrm{~cm}^{-1}$ by the Renishaw Invia Raman microscope laser source with $220 \mathrm{~mW}$ power operating and the spectral resolution is $\pm 2 \mathrm{~cm}^{-1}$. The observed FTIR and FT-Raman spectra are shown in Figs. 2 and 3.

\section{Computational Details}

The entire calculations were performed at density functional theory (DFT) levels on a HP Pavilion dv4/Intel(R)Core(TM) Duo CPU T6600 @ 2.20GHz personal computer using Gaussian 03W [36] program package, invoking gradient geometry optimization [37] using Hartree-Fock (HF) and Becke's three parameter hybrid functional (B3) [31] model using the Lee-Yang-Parr (LYP) correlation functional [32] (B3LYP) methods combined with standard 6-31+G $(\mathrm{d}, \mathrm{p})$ basis set. The Cartesian representation of the theoretical force constants have been computed at optimized geometry by assuming $\mathrm{C}_{s}$ point group symmetry. To satisfactorily describe the conformation and orientation of the chloro and carboxylic groups, a fully polarized $6-31+G(d, p)$ basis set are required and considered to be a complete basis sets. The optimized structural parameters were used in the Vibrational frequency calculations at the HF and DFT levels to characterize all stationary points as minima. The DFT hybrid B3LYP functional tends also to overestimate the fundamental modes; therefore scaling factors have to be used for obtaining a considerably better agreement with experimental data. Therefore, the scaling factors of 0.91 and 0.93 were uniformly applied to the HF for the $\mathrm{C}-\mathrm{H}$ stretching mode and others mode of vibrations respectively and also the scaling factors 0.96 and 0.99 were uniformly applied to the B3LYP for the C-H stretching mode and others mode of vibrations respectively calculated wavenumbers. The force constants were refined by damped least square fitting technique to achieve a close agreement between the observed and calculated Vibrational frequencies $[38,39]$.

\section{Results And Discussion}

\section{Molecular geometry}

The structure and the scheme of numbering the atom of 7-chloro-4-hydroxy-3-quinolinecarboxylic acid are represented in Fig.1 (a). The geometry of the molecules under investigation is considered by possessing $\mathrm{C}_{\mathrm{S}}$ point group symmetry.

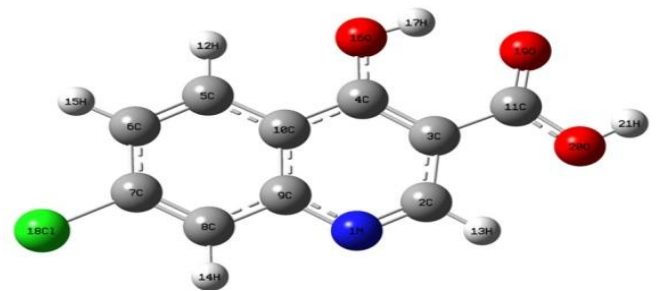

Fig.1. (a) Molecular structure of 7C4H3QCA

The molecule has 21 atoms and 57 normal modes of fundamental vibrations distributed into the irreducible representations under $\mathrm{C}_{\mathrm{S}}$ symmetry as 39 in-plane vibrations of $\mathrm{A}^{\prime}$ species and 18 out-of-plane vibrations $\mathrm{A}^{\prime \prime}$ species i.e.

$\Gamma_{\mathrm{Vib}}=39 \mathrm{~A}^{\prime}+18 \mathrm{~A}^{\prime \prime}$

All the frequencies are assigned in terms of fundamental, overtone and combination bands.

\section{Structural properties}

The optimized bond lengths and angles for the thermodynamically preferred geometry of 7-chloro-4hydroxy-3-quinolinecarboxylic acid determined at HF/6-31+G $(d, p)$ and B3LYP/6-31+G $(d, p)$ levels are represented in Table 1 in accordance with the atom numbering scheme of the molecule shown in Fig.1. (a). From the structural data presented in Table 1 it is observed that the internuclear distance of the rings atoms N1$\mathrm{C} 2$ is smaller than N1-C9 because the carboxylic group is attached with C3. 
Comparative vibrational spectroscopic studies of 7-chloro-4-hydroxy-3-quinolinecarboxylic acid

TABLE 1

Optimized geometrical parameters of 7-chloro-4-hydroxy-3-quinolinecarboxylic acid by HF and DFT/B3LYP calculations with the basis sets 6-31+G $(d, p)$

\begin{tabular}{|c|c|c|c|}
\hline \multirow{2}{*}{$\begin{array}{c}\text { Bond length } \\
\left(\mathbf{A}^{0}\right)\end{array}$} & \multicolumn{2}{|c|}{ Basis set $6-31+G(d, p)$} & \multirow{2}{*}{$\begin{array}{l}\text { Experimental } \\
\text { Value }\end{array}$} \\
\hline & HF & B3LYP & \\
\hline N1-C2 & 1.287 & 1.312 & 1.393 \\
\hline N1-C9 & 1.363 & 1.374 & 1.331 \\
\hline $\mathrm{C} 2-\mathrm{C} 3$ & 1.424 & 1.427 & 1.365 \\
\hline C2-H13 & 1.075 & 1.088 & - \\
\hline $\mathrm{C} 3-\mathrm{C} 4$ & 1.384 & 1.404 & 1.427 \\
\hline $\mathrm{C} 3-\mathrm{C} 11$ & 1.464 & 1.459 & - \\
\hline $\mathrm{C} 4-\mathrm{C} 10$ & 1.425 & 1.427 & 1.393 \\
\hline $\mathrm{C} 4-\mathrm{O} 16$ & 1.314 & 1.333 & - \\
\hline C5-C6 & 1.360 & 1.379 & 1.374 \\
\hline $\mathrm{C} 5-\mathrm{C} 10$ & 1.416 & 1.417 & 1.410 \\
\hline C5-H12 & 1.073 & 1.085 & - \\
\hline C6-C7 & 1.413 & 1.414 & 1.389 \\
\hline C6-H15 & 1.073 & 1.084 & - \\
\hline $\mathrm{C} 7-\mathrm{C} 8$ & 1.359 & 1.379 & 1.393 \\
\hline C7-Cl18 & 1.739 & 1.755 & - \\
\hline C8-C9 & 1.415 & 1.416 & 1.402 \\
\hline C8-H14 & 1.072 & 1.084 & - \\
\hline C9-C10 & 1.403 & 1.428 & 1.428 \\
\hline C11-O19 & 1.205 & 1.236 & 1.340 \\
\hline $\mathrm{C} 11-\mathrm{O} 20$ & 1.320 & 1.347 & 1.340 \\
\hline $\mathrm{O} 16-\mathrm{H} 17$ & 0.956 & 0.992 & - \\
\hline $\mathrm{O} 20-\mathrm{H} 21$ & 0.949 & 0.973 & - \\
\hline H17-O19 & 1.837 & 1.716 & - \\
\hline \multicolumn{4}{|l|}{ Bond angle (deg.) } \\
\hline C2-N1-C9 & 117.7 & 117.4 & 117.5 \\
\hline N1-C2-C3 & 124.9 & 124.8 & 123.8 \\
\hline N1-C2-H13 & 116.9 & 116.8 & - \\
\hline N1-C9-C8 & 117.8 & 117.8 & - \\
\hline N1-C9-C10 & 123.3 & 123.3 & 121.6 \\
\hline C3-C2-H13 & 118.2 & 118.4 & - \\
\hline C2-C3-C4 & 118.1 & 118.3 & 117.8 \\
\hline C2-C3-C11 & 122.0 & 122.7 & - \\
\hline C4-C3-C11 & 120.0 & 118.9 & - \\
\hline C3-C4-C10 & 118.4 & 118.5 & 121.4 \\
\hline C3-C4-O16 & 124.2 & 123.1 & - \\
\hline C3-C11-O19 & 123.9 & 123.8 & - \\
\hline C3-C11-O20 & 114.7 & 115.2 & 119.0 \\
\hline C10-C4-O16 & 117.4 & 118.3 & 119.0 \\
\hline C4-C10-C5 & 122.3 & 122.5 & 117.7 \\
\hline C4-C10-C9 & 117.7 & 117.6 & 118.8 \\
\hline C4-O16-H17 & 110.5 & 107.5 & - \\
\hline C6-C5-C10 & 120.4 & 120.5 & 119.6 \\
\hline C6-C5-H12 & 120.5 & 120.5 & - \\
\hline C5-C6-C7 & 119.1 & 119.2 & 121.4 \\
\hline C5-C6-H15 & 121.2 & 121.0 & - \\
\hline C10-C5-H12 & 119.2 & 119.1 & - \\
\hline C5-C10-C9 & 120.0 & 119.9 & - \\
\hline C7-C6-H15 & 119.7 & 119.8 & - \\
\hline C6-C7-C8 & 122.1 & 121.9 & - \\
\hline C6-C7-C118 & 118.2 & 118.4 & - \\
\hline C8-C7-C118 & 119.7 & 119.6 & - \\
\hline C7-C8-C9 & 119.5 & 119.6 & 119.6 \\
\hline C7-C8-H14 & 121.9 & 121.9 & - \\
\hline C9-C8-H14 & 118.6 & 118.5 & - \\
\hline C8-C9-C10 & 119.0 & 118.8 & 121.4 \\
\hline O19-C11-O20 & 121.4 & 121.0 & 118.0 \\
\hline C11-O19-H17 & 100.8 & 100.5 & - \\
\hline C11-O20-H21 & 108.9 & 107.2 & - \\
\hline O16-H17-O19 & 140.6 & 146.1 & - \\
\hline
\end{tabular}

The shorter internuclear distance of N1-C2 Indicates that the benzene ring exerts larger attraction on valance electron cloud of nitrogen atom resulting in easy delocalization of lone pair of electrons into the ring and thereby increase in force constant and decrease in internuclear distance. The internuclear distance of the ring carbons atoms C2-C3 and C9-C10 are very close to each other at B3LYP levels of calculations but the others C$\mathrm{C}$ of the ring seems to be slightly differ to each other's and C3-C11 is much longer than others. The internuclear distance C7-C118 and H17-O19 are much longer than the others like C-N, C-C, C-H and O-H. The internuclear distances of C2-H13, C5-H12, C6-H15 and C8-H14 are approximately same. Similarly the internuclear distance of $\mathrm{O}-\mathrm{H}$ atoms in hydroxyl group and also the internuclear distance of $\mathrm{C}-\mathrm{O}$ atoms are approximately same. The bond angles $\mathrm{C} 2-\mathrm{C} 3-\mathrm{C} 11$ and $\mathrm{C} 4-\mathrm{C} 10-\mathrm{C} 5$ are very close to each other and the angle $\mathrm{C} 2-\mathrm{C} 3-\mathrm{C} 11$ very large and the angle $\mathrm{C} 4-\mathrm{C} 10-\mathrm{C} 9$ is very small than the others $\mathrm{C}-\mathrm{C}-\mathrm{C}$ bond angles. The others $\mathrm{C}-\mathrm{C}-\mathrm{C}$ bond angles are 
Comparative vibrational spectroscopic studies of 7-chloro-4-hydroxy-3-quinolinecarboxylic acid

approximately same. With the electron donating substituent's on the benzene ring, the symmetry of the ring is distorted, yielding ring angles smaller than $120^{\circ}$ at the point of substitution and slightly larger than $120^{\circ}$ at the ortho and meta positions [40]. Similar trend is observed in 7C4H3QCA molecule where the bond angle C5-C6$\mathrm{C} 7$ is around $119.2^{0}$ while at para, N1-C2-C3 and C2-C3-C4 positions the angles are found to be around $124.8^{0}$ and $118.3^{\circ}$, respectively. Introduction of nitrogen atom leads to significant perturbations in the hetero substituted ring of quinoline moiety, although the structural properties of the benzene ring are seen to be relatively unperturbed. The bond angle of O16-H17-O19 is very large and the angle C11-O19-H17 is very small than the others bond angle. The bond angles $\mathrm{C} 3-\mathrm{C} 4-\mathrm{O} 16$ and $\mathrm{C} 3-\mathrm{C} 11-\mathrm{O} 19$ are very close to each other and the angle $\mathrm{C} 3-$ C11-O19 is very large but the angle $\mathrm{C} 3-\mathrm{C} 11-\mathrm{O} 20$ is very small than $\mathrm{C} 10-\mathrm{C} 4-\mathrm{O} 16$ bond angle. From theoretical values we can find that most of the optimized bond lengths and bond angles are slightly longer and shorter than experimental values. Comparing bond angles and bond lengths of 7C4H3QCA molecule at B3LYP/6-31+G (d, p) method leads to geometrical parameters which are much closer to experimental values [70].

\section{Vibrational analysis}

The observed Vibrational assignments and analysis of 7-chloro-4-hydroxy-3-quinolinecarboxylic acid are discussed in terms of fundamental bands, overtones and combination bands. The experimental FT-IR and FTRaman spectra of 7C4H3QCA are shown in Figs. 2 and 3 respectively. Due to the fluorescent nature of the compound, the peaks in Raman spectra are not observed. The computational theoretical FT-IR and FT-Raman spectra of 7C4H3QCA are shown in Figs. 4 and 5. The observed and calculated unscaled and scaled vibrational frequencies along with their relative species, IR Intensity, Raman activity, reduced mass, force constants along with the depolarization ratios and most probable assignments with standard higher basis set $6-31+\mathrm{G}(\mathrm{d}, \mathrm{p})$ force field are collected in Table 2. Comparison of the frequencies calculated at B3LYP with the experimental values (in Table 2) reveals the overestimation of the calculated vibrational modes, due to neglect of anharmonicity in real system. Inclusion of electron correlation in density functional theory to a certain extend makes the frequency values smaller in comparison with the HF frequency data. Reduction in the computed harmonic vibrations, though basis set sensitive are marginal as observed in the DFT values using $6-31+G(d, p)$.

\section{Skeletal Vibrations}

\section{C-C and C-N Vibrations}

The carbon-carbon stretching modes of the phenyl group are expected in the range from 1650 to $1200 \mathrm{~cm}^{-1}$. The actual position of these mode are determined not so much by the nature of the substituent but by the form of substitution around the ring [41], although heavy halogens cause the frequency to diminish undoubtedly [42]. In 7C4H3QCA under $\mathrm{C}_{\mathrm{S}}$ symmetry the carbon-carbon stretching bands appearing in the infrared spectrum at 1698, 1463 and $1352 \mathrm{~cm}^{-1}$ are assigned to skeletal C-C bonds while the bands at $1698 \mathrm{~cm}^{-1}$ have been also assigned to the ring $\mathrm{C}-\mathrm{N}$ stretching vibrations with $\mathrm{C}-\mathrm{C}$ vibrations but no bands are observed in the Raman spectra. The corresponding $\mathrm{C}-\mathrm{C}$ and $\mathrm{C}-\mathrm{N}$ stretching modes observed in the IR spectrum are given in Tables 2 . The bands occurring at $1113,907,790,616,515$ and $471 \mathrm{~cm}^{-1}$ in the infrared but no bands are observed in the Raman spectra are assigned to the skeletal C-C-C/C-N-C in-plane bending modes of 7C4H3QCA. The other in plane bending vibrations of the ring modes are calculated through HF and DFT methods. The out-of-plane bending ring vibrations under $\mathrm{C}_{S}$ symmetry are assigned to the bands at 758,673 and $436 \mathrm{~cm}^{-1}$ and the other out-of-plane bending vibrations of the ring modes are calculated through HF and DFT methods. The results are in good agreement with the literature values [43-46]. The density functional theory analysis shows that significant mixing of skeletal in-plane bending with $\mathrm{C}-\mathrm{H}$ in-plane bending and vice versa occurs. In benzene the ring breathing $\left(a_{1 g}\right)$ vibrations exhibit the characteristic frequencies at $995 \mathrm{~cm}^{-1}$ [42]. In 7C4H3QCA the ring deformation and ring breathing mode are observed at 930 and $718 \mathrm{~cm}^{-1}$ respectively in the infrared spectrum. 
Comparative vibrational spectroscopic studies of 7-chloro-4-hydroxy-3-quinolinecarboxylic acid

TABLE ?

Assigument of fundamental ribrations of 7 -chloro-4-bydroxy-3-quinolinecarboxyglic acid calculations using from HF and DFT/BJLYP basis set $6-31+G(d, p)$

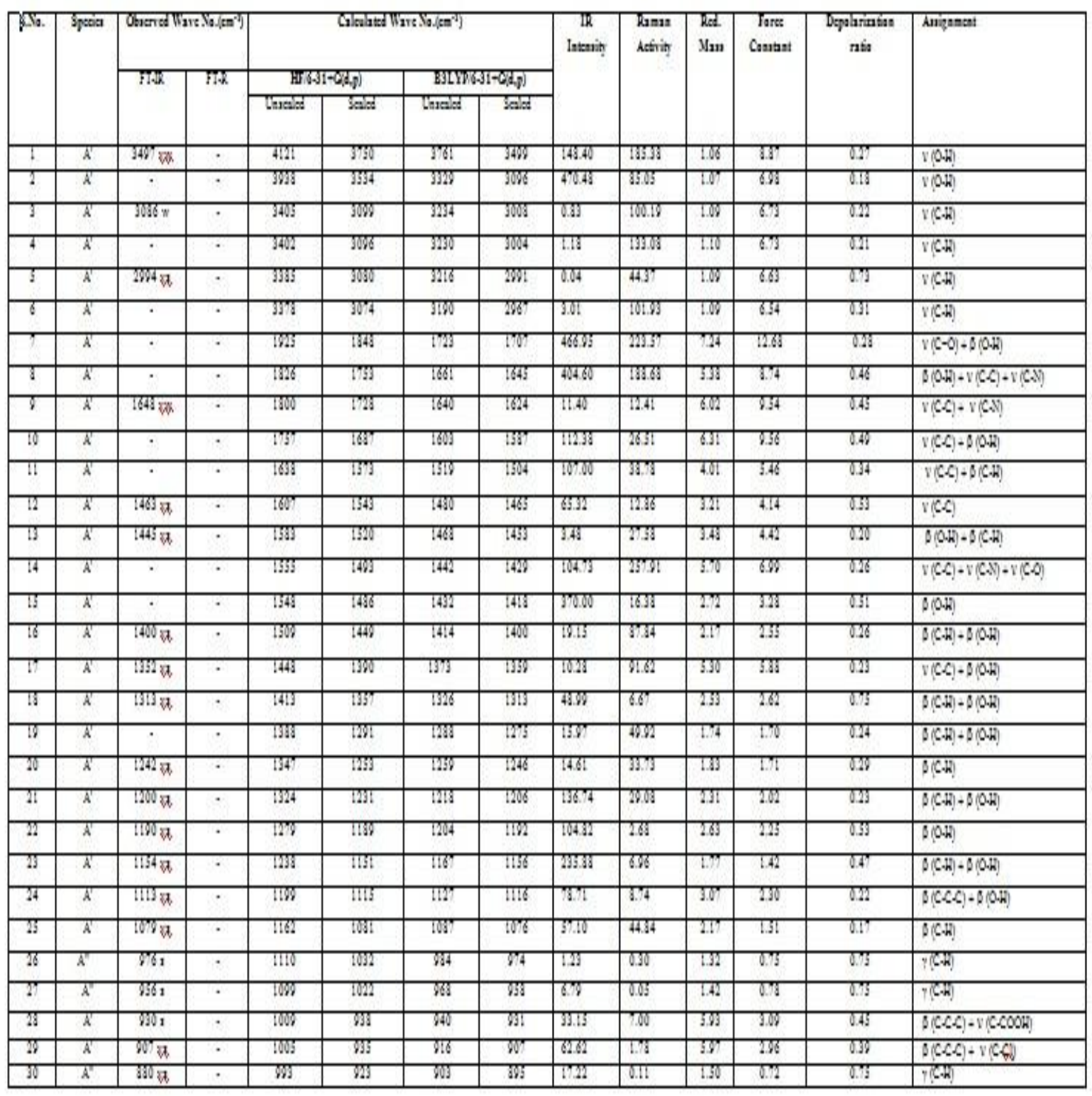


Comparative vibrational spectroscopic studies of 7-chloro-4-hydroxy-3-quinolinecarboxylic acid TABLE 2 cont....

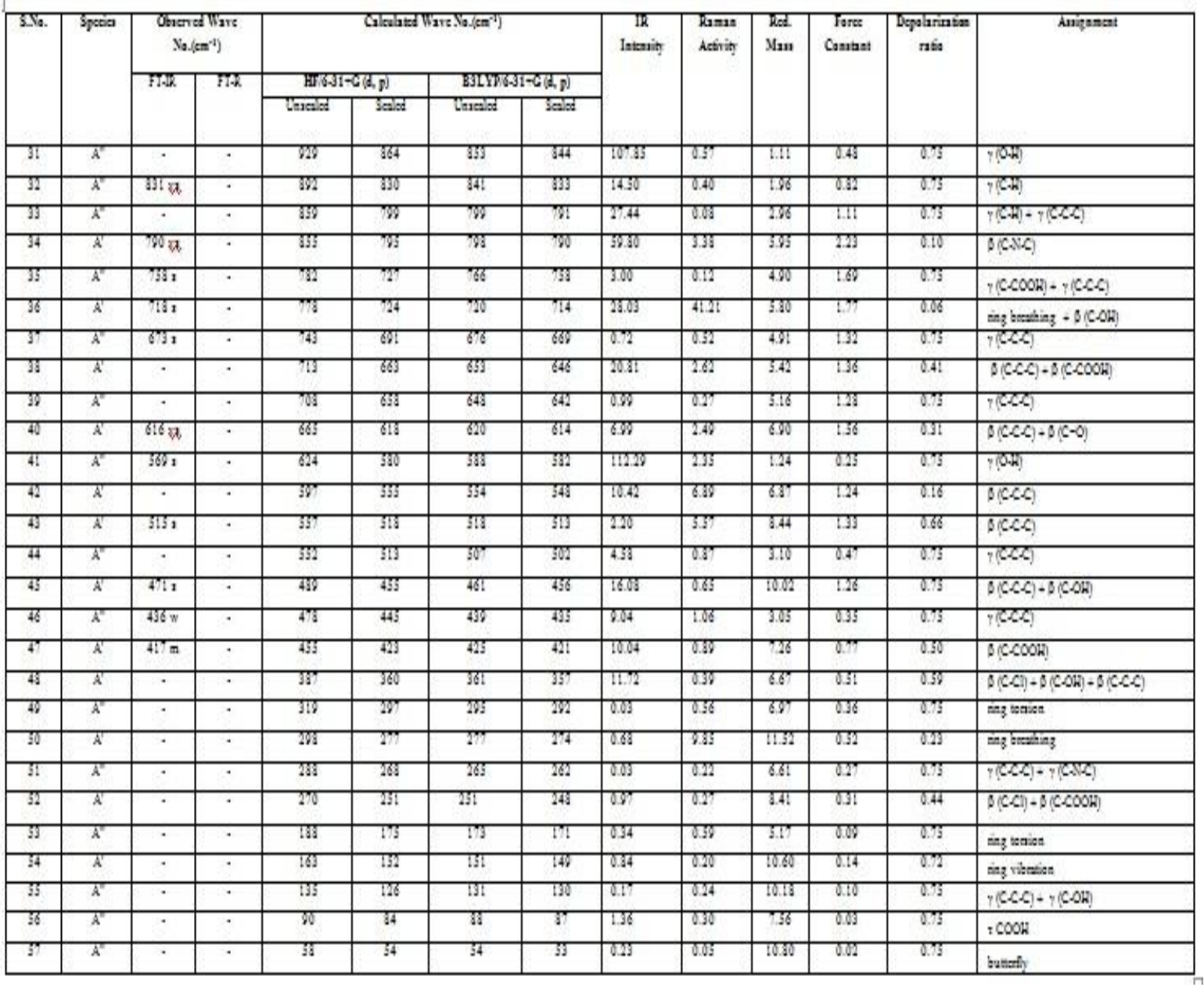

Where

$\mathrm{s}$ - strong, vs - very strong, $\mathrm{m}$ - medium, w- weak, vw - very weak, $v$ - stretching, $v_{\mathrm{s}^{-}}$symmetric stretching, $v_{a^{-}}$anti symmetric stretching, $\beta$ - in-plane bending, $\gamma$ - out-of-plane bending, $\tau$ torsion/twisting, $\omega$ - wagging, $\rho$ - rocking, wavenumbers $\left(\mathrm{cm}^{-1}\right)$, IR intensities ( KM/mole ), Raman activities $\left(\mathrm{A}^{0}\right)^{4} /$ (a.m.u.), reduced mass ( a.m.u. ), force constant $\left(\mathrm{mdyn} / \mathrm{A}^{0}\right.$ )

\section{C-H Vibrations}

The aromatic C-H stretching vibrations are normally found between 3100 and $3000 \mathrm{~cm}^{-1}$. The C-H stretching of 7C4H3QCA gives bands at 3086 and $2994 \mathrm{~cm}^{-1}$ in FT-IR but no bands are observed in the FTRaman spectra. The potential energy distribution contribution of the aromatic stretching modes indicates that these are also highly pure modes as carbon-carbon stretching. The $\mathrm{C}-\mathrm{H}$ in-plane bending modes are normally observed in the region 1350-950 $\mathrm{cm}^{-1}$. These modes are observed in 7C4H3QCA at 1445, 1400, 1313, 1242, 1200,1154 and $1079 \mathrm{~cm}^{-1}$. The C-H out-of-plane bending modes are observed in the region $950-600 \mathrm{~cm}^{-1}$. The aromatic C-H out-of-plane bending vibrations of 7C4H3QCA are assigned to the bands observed at 976, 956, 880 and $831 \mathrm{~cm}^{-1}$ and these bands occurred in the said region [46-48]. The density functional theory analysis reveals that the aromatic $\mathrm{C}-\mathrm{H}$ in-plane and out-of-plane bending vibrations have substantial overlapping with the ring $\mathrm{C}-\mathrm{C}-\mathrm{C}$ in-plane and out-of-plane bending modes, respectively. All these $\mathrm{C}-\mathrm{H}$ in-plane and out-of-plane bending modes of the compound are also assigned within the said region and are presented in Table 2 .

\section{Combination and Overtones of aryl ring vibrations}

According to Kalsi [49], usually intense overtones of aryl ring vibrations occur in the region 2000-1650 $\mathrm{cm}^{-1}$. These bands are somewhat weaker than fundamentals and are most clearly seen in the spectra of moderately thick samples. In the present study, in the infrared bands observed in the region 1943, 1917, 1861, 1837, 1801, 1788 and $1698 \mathrm{~cm}^{-1}$ has been assigned to combination and overtone of aryl ring vibrations are shown in infrared spectra Fig. 2. These assignments are further in agreement with the standard literature [50, 51]. But these vibrations could not be seen in the theoretical FT-IR and FT-Raman spectra. 
Comparative vibrational spectroscopic studies of 7-chloro-4-hydroxy-3-quinolinecarboxylic acid

\section{Group Vibrations}

\section{C-Cl Vibrations}

Strong characteristic absorption due to C-X stretching vibration is observed and the position of the band is influenced by neighbouring atoms or groups, the smaller the halide atom, the greater the influence of the neighbour. Unlike aliphatic compounds there appears to be no pure C-X stretching vibration band for aromatic halogen compounds $[48,52]$. The $\mathrm{C}-\mathrm{Cl}$ stretching absorption is observed in the broad region between 850-505 $\mathrm{cm}^{-1}$. When several chlorine atoms are attached to one carbon atom, the band is usually more intense and at high frequency end of the assigned limits due to the asymmetric and symmetric modes [53-57]. Vibrational coupling with other groups may result in a shift in the absorption to as high as $907 \mathrm{~cm}^{-1}$. In view of this, the very strong band in FT-IR at $907 \mathrm{~cm}^{-1}$ is assigned to the $\mathrm{C}-\mathrm{Cl}$ stretching of 7C4H3QCA. The $\mathrm{C}-\mathrm{Cl}$ in-plane bending mode of 7C4H3QCA is observed at 361 in infrared only theoretically observed. These assignments are in good agreement with the literatures $[53,58]$. The $\mathrm{C}-\mathrm{Cl}$ in-plane mode is significantly overlapped with $\mathrm{C}-\mathrm{H}$ and $\mathrm{CCC}$ in-plane bending modes and vice versa.

\section{-OH (hydroxyl) and - $\mathrm{COOH}$ (carboxylic acid) group vibrations}

The hydroxyl stretching vibrations are generally [59] observed in the region around $3500 \mathrm{~cm}^{-1}$. The O$\mathrm{H}$ group vibrations are likely to be the most sensitive to the environment, so they show pronounced shifts in the spectra of the hydrogen bonded species. The bands due to the $\mathrm{O}-\mathrm{H}$ stretching are of medium to strong intensity in the infrared spectrum, although it may be broad. In Raman spectra the band is generally very weak or not observed. The strong band appeared at $3497 \mathrm{~cm}^{-1}$ in the FT-IR spectra is assigned to O-H stretching mode of vibration. The $\mathrm{O}-\mathrm{H}$ in-plane bending vibration is observed in the region $1260-1440 \mathrm{~cm}^{-1}$ [60]. The $\mathrm{O}-\mathrm{H}$ out-ofplane deformation vibrations for phenol lies in the region $290-320 \mathrm{~cm}^{-1}$ for free $\mathrm{O}-\mathrm{H}$ and in the region $517-710$ $\mathrm{cm}^{-1}$ for associated $\mathrm{O}-\mathrm{H}$ [42]. In both inter-molecular and intra-molecular associations, the wavenumber is at higher value than that in the free $\mathrm{O}-\mathrm{H}$. The wavenumber increases with hydrogen bond strength because of large amount of energy required to twist the $\mathrm{O}-\mathrm{H}$ bond [61]. The calculated values of in-plane/out-of-plane bending vibrations of hydroxyl groups are 1445, 1400, 1352, 1313, 1242, 1200, 1190, 1154 and $1113 \mathrm{~cm}^{-1} / 569 \mathrm{~cm}^{-1}$, respectively. The carbonyl group is most important in the infrared spectrum because of its strong intensity of absorption and high sensitivity toward relatively minor changes in its environment. Intra and intermolecular factors affect the carbonyl absorptions in common organic compounds due to inductive, mesomeric effects, field effects and conjugation effects. The C-O stretching bands of acids are considerably more intense than the ketonic $\mathrm{C}-\mathrm{O}$ stretching bands. The characteristic infrared absorption wavenumber of $\mathrm{C}-\mathrm{O}$ in acids are normally strong in intensity. The $\mathrm{CO} 2$ stretching vibration in the spectra of carboxylic acid gives rise to strong band in the region $1675-1750 \mathrm{~cm}^{-1}$ [62]. The very strong bands observed in the FT-IR at 1707 and $1429 \mathrm{~cm}^{-1}$ are assigned to $\mathrm{C}-\mathrm{O}$ stretching vibration. But these vibrations are not experimentally observed. The strong bands observed in the FT-IR at 718, 616 and $417 \mathrm{~cm}^{-1}$ are assigned to C-O in-plane bending vibrations. The two $\mathrm{COOH}$ torsional modes are expected in the region $150-50 \mathrm{~cm}^{-1}$ and found in the low wavenumber region [62]. This mode of vibration is found theoretically at $88 \mathrm{~cm}^{-1}$. The anharmonic frequency predicted at $931 \mathrm{~cm}^{-1}$ by B3LYP/6-31+G $(d, p)$ method is assigned to C-COOH stretching vibration which is observed at $930 \mathrm{~cm}^{-1}$ in the FT-IR spectra. The $\mathrm{C}-\mathrm{COOH}$ in-plane bending and out-of-plane bending vibrations were not observed experimentally, so that these modes are assigned on the potential energy distribution. The potential energy distributions of these modes are mixed one as it is shown in Table 2. The correction factors used to correlate the experimentally observed and theoretically computed frequencies for each Vibrational modes of 7C4H3QCA under HF and DFT-B3LYP methods are similar and an explanation of this approach were discussed previously [63].

\section{Vibrations due to tautomerism}

Spectral studies establish that N-hetrocyclic substituted by $-\mathrm{OH},-\mathrm{SH}$ and $-\mathrm{NH}_{2}$ groups exhibit tautomerism. In sharp contrast to other heterocyclic system, several of these bases found in nature alkaloids and nucleic acid were found to exist predominantly in the keto or amino forms. Keto-enol, thione-thiol and aminoimino tautomerism have been long and are still evoked as the major and even unique, source of spontaneous mutagenesis. Apart from its presumes relevance to spontaneous and induced mutagenesis, such tautomerism is of major significance in the structure of alkaloids nucleic acid and is of current additional importance in relation to the antimetabolic activity of alkaloids, nucleie acid and of some N-hetrocyclic aromatic ring analogous [64]. Although both infrared and ultraviolet spectroscopy may be employed for studies on tautomeric equilibrium yet as shown by Nowak et al. [65], the former is by far the more accurate and unequivocal in interpretation. In the present investigation of $7 \mathrm{C} 4 \mathrm{H} 3 \mathrm{QCA}$, the molecule is supposed to show tautomeric behaviour. 
It is interesting to note additional N-H and O-H stretching and bending frequencies in the present study, showing the presence of both hydrogen bonding and tautomerism. Hydrogen bonding can occur in any system containing proton donor group and a proton acceptor group [66].

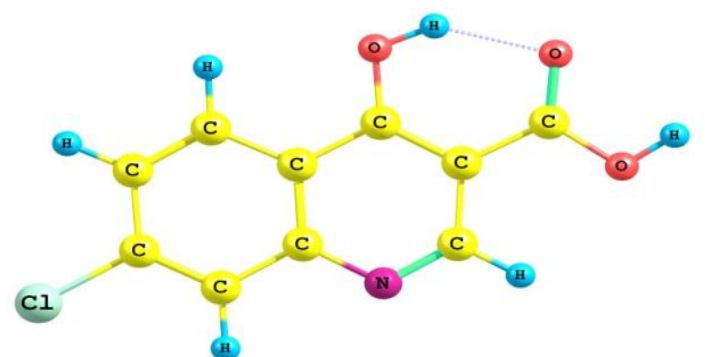

Fig.1. (b) Hydrogen bonding shown by 7C4H3QCA

The organic molecules, the common proton donar groups are carboxyl, hydroxyl, amine or amide group and common proton acceptor atoms are oxygen, nitrogen and halogens. The 7C4H3QCA has one proton donor group (i.e. hydroxyl group) and one proton acceptor atom (i.e. $\mathrm{N}$-atom of the quinoline ring). According to Hoyer [67], the stretching frequency of the O-H group of benzyl alcohol is $3640 \mathrm{~cm}^{-1}$. When the group is free and it decreases $3350 \mathrm{~cm}^{-1}$ when associated. Similar frequency drops are observed for the O-H stretching of phenol and carboxylic acid [41]. In the present investigation the weak infrared band at $3497 \mathrm{~cm}^{-1}$ has been assigned to bond $\mathrm{O}-\mathrm{H}$ stretching. The stretching frequency of the acceptor group is also reduced, but to a lesser degree than proton donor group [64]. According to Silverstein [68], the bending vibrations of hydrogen bonded group usually shifts to a shorter wavelength (long frequency) this shift is less pronounced than that of stretching frequency. Evans [69] studied the behaviour of the out-of-plane $-\mathrm{OH}$ vibration of phenol derivatives as a function of the strength of hydrogen bond. He established the frequency value is $650 \mathrm{~cm}^{-1}$ in the middle of the chain, while it is $300 \mathrm{~cm}^{-1}$ in the free state. In the present investigation, the FT-IR band at $569 \mathrm{~cm}^{-1}$ has been assigned to out-of-plane bending mode of free $-\mathrm{OH}$ group.

\section{Computed IR intensity and Raman activity analysis}

Computed vibrational spectral IR intensities and Raman activities of the corresponding wave numbers by B3LYP/6-31+G (d, p) basis set have been collected in Table 2. The IR intensities and Raman activities calculated by B3LYP/6-31+G (d, p) level with experimental values exposes the variation of IR intensities and Raman activities. These variations may be due to the substitution of the hydroxyl and electronegative atom.

\section{Vibrational force constant}

The output files of the quantum mechanical calculations contain the force constants matrix in cartesian co-ordinates and in mdyn $/ \mathrm{A}^{0}$ units. These force constants were transformed to the force fields in the internal local-symmetry co-ordinates. The force field determined was used to calculate the vibrational potential energy distribution among the normal co-ordinate. In the molecule the values show the variation due to the substitutions of the halogen and hydroxyl groups. They are listed in Table 2.

A better agreement between the computed and experimental frequencies can be obtained by using different scale factors for different regions of vibrations. Initially, all scaling factors have been kept fixed at a value. The correction factors used to correlate the experimentally observed and theoretically computed frequencies for each Vibrational modes of 7C4H3QCA under HF and DFT-B3LYP methods are similar and an explanation of this approach was discussed previously [70-77]. Subsequently, in HF method a scale factor of 0.91 rings $\mathrm{C}-\mathrm{H}$ and $\mathrm{O}-\mathrm{H}$ stretching modes while 0.93 for the all other vibrations are used. In B3LYP level a scale factor of 0.96 for $\mathrm{C}-\mathrm{H}$ and $\mathrm{O}-\mathrm{H}$ stretching vibrations and 0.99 for other fundamental modes have been utilized to obtain the scaled frequencies of the compound 7C4H3QCA with 6-31+G (d, p) basis set. The scale factors used in this study minimized the deviations very much between the computed and experimental frequencies both at HF and DFT/B3LYP level of calculations. DFT/B3LYP correction factors are all much closer to unity than the HF correction factor, which means that the DFT/B3LYP frequencies are very much closer to the experimental values than the HF frequencies. Thus, Vibrational frequencies calculated by using the B3LYP functional with $6-31+\mathrm{G}(\mathrm{d}, \mathrm{p})$ basis set can be utilized to eliminate the uncertainties in the fundamental assignments in infrared Vibrational spectra [78]. 


\section{Conclusions}

FT-IR and FT-Raman, quantum chemical calculation studies have been performed on 7-chloro-4hydroxy-3-quinolinecarboxylic acid, in order to identify its structural and spectroscopic features. Attempts have been made in the present work for the proper frequency assignments for the compound 7C4H3QCA from the FT-IR and FT-Raman spectra. The equilibrium geometries and harmonic frequencies of 7C4H3QCA were determined and analyzed both at HF and DFT level of theories utilizing 6-31+G(d,p) basis set, giving allowance for the lone pairs through diffuse functions. Comparison between the calculated Vibrational frequencies and the experimental values indicates that the methods of B3LYP/6-31+G $(d, p)$ and HF/6-31+G $(d, p)$ can predict the IR and laser Raman spectra of the title compound well. Any discrepancy noted between the observed and the calculated frequencies may be due to the fact that the calculations have been actually done on single molecules in the gaseous state contrary to the experimental values recorded in the presence of intermolecular interactions. The optimized geometry parameters calculated at B3LYP/6-31+G $(\mathrm{d}, \mathrm{p})$ are slightly larger than those calculated at $\mathrm{HF} / 6-31+\mathrm{G}(\mathrm{d}, \mathrm{p})$ level and the HF calculated values coincides well compared with the experimental data on the whole. The difference between the observed and scaled wave number values of most of the fundamentals is very small. The observed and the calculated frequencies are found to be in good agreement.

\section{Acknowledgement}

Authors are thankful to Central Instruments Facility (CIF) - USIC, University of Delhi, for recording the FT-IR and FT-Raman spectra of the said compound.

\section{References}

[1]. Sakai S, Minoda K, Saito G, Akain S, Ueno A, Fukuka F,Gann,Vol.46, 605 (1955).

[2]. Katzung B G, "Basic and Clinical Pharmacology", Appleton and Lange, Prentice-Hall,

[3]. Lebanon, (1989).

[4]. World Health Organization, “The World Health Report: 2002: Reducing Risks", Promoting Healthy Life.

[5]. Ginsburg H, Famin O, Zhang J, Krugliak M, Biochem. Pharmacol, Vol.56, (1998) 1305.

[6]. Loria P, Miller S, Foley M, Tilley L, Biochem. J., Vol.339, 363 (1999).

[7]. Egan T J et al., Biochem. J., Vol.365, 343 (2002).

[8]. Egan T J, Drug Design Rev., 1, 93 (2004).

[9]. Buller R, Peterson M L, Almarsson M, Leiserowitz L, Cryst. Growth Des., 2, 553 (2002).

[10]. De D, Krogstad F M, Cogswell F B, Krogstad D J, Am. J. Trop. Med. Hyg. ,55, 579 (1996).

[11]. Casabianca L B, De Dios A C, J. Phys. Chem.,Vol.A110, 7787 (2006).

[12]. Casabianca L B, Faller C M, De Dios A C, J. Phys. Chem., Vol.A110, 234 (2006).

[13]. Rafiee M A, Hadipour N L, Naderi-manesh H, J. Comput. Aid. Mol. Des., 18, 215 (2004).

[14]. Paragi G, Van Alsenoy C, Penke B, Timar Z, J. Mol. Struct.,Theochem.,Vol.666/667, 123(2003).

[15]. Krishnakumar V, Ramasamy R, Spectrochim. Acta, Vol.61A, 673 (2005).

[16]. Dziembowska T, Szafran M, Jagodzinska E, Natkaniec I, Pawlukoj A, Kwiatkowski J S, J. Baran, Spectrochim. Acta, Vol.59A, 2175 (2003).

[17]. Ozel A E, Kecel S, Akyuz S, Vib. Spectrosc., Vol.42, 325 (2006)

[18]. Leroux N, Goethals M, Th. Zeegers-Huyskens, Vib. Spectrosc., Vol.9, 235 (1995).

[19]. Zwaans R, Thomson C, J. Mol. Struct.: Theochem., Vol.362, 51 (1996).

[20]. Zarur F N, Reyes R V, J. Mol. Struct.: Theochem., 850, 127 (2008).

[21]. Bahgat K, Ragheb A G, Cent. Eur. J. Chem., Vol.5, 201 (2007).

[22]. Arici K, Yurdakul M, Yurdakul S, Spectrochim. Acta Part A, Vol.61A, 37 (2005).

[23]. Mphahlele M J, El-Nahas A M, El-Gogary T M, J. Mol. Struct.,690, 151 (2004).

[24]. Ozel A E, Buyukmurat Y, Akyuz S, J. Mol. Struct.,565/566, 455 (2001).

[25]. Engelter C, Jackson G E, Knight C L, Thornton D A, J. Mol. Struct., 213, 133 (1989).

[26]. Turker L, Yildırır Y, J. Mol. Struct.: Theochem., 676, 47 (2004).

[27]. Tokay N, Ogretir C, J. Mol. Struct.: Theochem., 594, 185 (2002).

[28]. Camargo A J, Napolitano H B, Zukerman-Schpector J, J.Mol. Struct., Theochem.,816, 145 (2007).

[29]. Shashidar M A, Rao K S, Ind. J. Phys.,Vol.41, 299 (1967).

[30]. Golcuk K, Altun A, Kumru M, Spectrochim. Acta Part A, Vol.59A, 1841 (2003).

[31]. Vaschetto M E, Retamal B A, Monkman A P, J. Mol. Struct.: Theochem., 468, 209 (1999).

[32]. Becke A D, J. Chem. Phys., Vol.98, 5648 (1993).

[33]. Lee C, Yang W, Parr R G, Phys. Rev., Vol.B37, 785 (1988).

[34]. Forsyth D A, Sebag A B, J. Am. Chem. Soc., Vol.119, 9483 (1997).

[35]. Becke A D, Phys. Rev., Vol.A38, 3098 (1988)

[36]. Hohenberg P, Kohn W, Phys. Rev., 136, B864 (1964).

[37]. Frisch M J, Trucks G W, Schlegel H B, Scuseria, G E, Robb M A, Cheeseman J R,Montgomery Jr. J A, Vreven T, Kudin K N, Burant J C, Millam J M, Iyengar S S, Tomasi J, Barone V, Mennucci B, Cossi M, Scalmani G, Rega N, Petersson G A, Nakatsuji H, Hada M, Ehara M, Toyota K, Fukuda R, Hasegawa J, Ishida M, Nakajima T, Honda Y, Kitao O, Nakai H, Klene M, Li X, Knox J E, Hratchian H P, Cross J B, Adamo C, Jaramillo J, Gomperts R, Stratmann R E, Yazyev O, Austin A J, Cammi R, Pomelli C, Ochterski J W, Ayala P Y, Morokuma K, Voth A, Salvador P, Dannenberg J J, Zakrzewski V G, Dapprich S, Daniels A D, Strain,O. Farkas M C, Malick D K, Rabuck A D, Raghavachari K, Foresman J B, Ortiz J V, Cui Q, Baboul A G, Clifford S, Cioslowski J, Stefanov B B, Liu G, Liashenko A, Piskorz P, Komaromi I, Martin R L, Fox D J, Keith T, Al-Laham M A, Peng C Y, Nanayakkara A, Challacombe M, Gill P M W, Johnson B, Chen W, Wong M W, Gonzalez C, Pople J A, Gaussian Inc., Wallingford, CT, (2004).

[38]. Schlegel H B, J. Comput. Chem., Vol.3, 214 (1982).

[39]. Daniel Glossman-Mitnik,Spectrochimica Acta Part A,Vol.66A, 208 (2007).

[40]. Dhanuskodi S, Manivannan S, J. Philip, Spectrochimica Acta Part A, Vol.69A, 1207 (2008). 
Comparative vibrational spectroscopic studies of 7-chloro-4-hydroxy-3-quinolinecarboxylic acid

[41]. Wang Y, Saebo S, Pittman Jr. C U, J. Mol. Struct. Theochem. , Vol.281, 91 (1993).

[42]. Bellamy L J, "The Infrared Spectra of Complex Molecules", 3rd ed., Wiley, New York, (1975).

[43]. Varsanyi G, “Assignments for Vibrational Spectra of Seven Hundred Benzene Derivaties”, vol.1, Adam Hilger, London, (1974).

[44]. Green J H S, Harrison D J, Spectrochim. Acta, Vol.29A, 1177 (1973).

[45]. Mohan S, Puviarasan N, Ilangovan V, Arab. J. Sci. Eng., Vol.1A, 25 (2000).

[46]. Arjunan V, Mohan S, Subramanian S, Thimme Gowda B, Spectrochim. Acta Part A,Vol.60A, 1141 (2004).

[47]. Arjunan V, Mohan S, Ravindran P, Mythili C V, Spectrochim. Acta part A, Vol.72, 783 (2009)

[48]. Arjunan V, Puviarasan N, Mohan S, Spectrochim. Acta Part A, Vol.64A, 233 (2006).

[49]. Altun A, Golcuk K, Kumru M, J. Mol. Struct.: Theochem., 637, 155 (2003).

[50]. Kalsi P S, "Spectroscopy of organic Compounds", New Age International (P) Ltd.,New Delhi,(2001).

[51]. Kasha M, Discro Faraday Soc, 9, 14 (1954).

[52]. Colthup N B, Daly L H and Wiberley S E, "Introduction to Infrared and RamanSpectroscopy", Scademic Press, New York,San Frnascisco, London,(1975).

[53]. Kurt M, Yurdakul M, Yurdakul S, J. Mol. Struct. Theochem., 711, 25 (2004).

[54]. Socrates G, "Infrared and Raman Characteristic Group Frequencies", 3rd ed., John Wiley \& Sons Ltd., Chichester, England, (2001).

[55]. Yadav R A, Singh I S, Spectrochim. Acta Part A,Vol.41A, 191 (1985).

[56]. Nyquist R A, The Interpretation of Vapour-Phase Spectra, Sadtler, (1985).

[57]. Soliman M S, Spectrochim. Acta Part A,Vol.49A, 189 (1993).

[58]. Khaled Bahgat, Abdel Ganie Ragheb, CEJC, Vol.5 (1), 201(2007).

[59]. Edwards H G M, J. Mol. Struct., 263, 11 (1991).

[60]. Michalska D, Bienko D C, Bienko A J A, Latajaka Z, J. Phys. Chem.,Vol.100, 17786 (1996).

[61]. Sathyanarayana D N, "Vibrational Spectroscopy Theory and Applications", seconded., New Age International (P) Limited Publishers, New Delhi, (2004).

[62]. Sadekov I D, Russ. Chem. Rev., 30, 179 (1970).

[63]. Roeges N P G, “A Guide to Complete Interpretation of Infrared Spectra of Organic Structures”, Wiley, New York, (1994).

[64]. Chaitanya K, Spectrochimica Acta Part A, Vol.86, 159 (2012).

[65]. Hadzi D, Skrbljak M, J Chem Soc, Londan, 843 (1957).

[66]. Nowak M J, Szezeniak K, Barski A, Shugar D, Naturforsch, J Chem Soc, Vol.33, 876 (1978).

[67]. Yadav B S, Kumar Vipin, Yadav M K and Yadav I R, Acta Botanica Indica, Vol.26, 15 (1998).

[68]. Hoyer W and Howath G A, Chem Abstr, Vol.78, 1608H (1973)

[69]. Silverstein R M, Bassler G C and Morill T C, "Spectrometric Identification of Organic Compounds", John Wile and Sons, New York, (1981).

[70]. Evans J C, Spectrochimica Acta, Vol.16, 428 (1960)

[71]. Lakshmi A, Balachandran V, Janaki A, J. Mol. Structure, 1004, 51(2011).

[72]. V. Arjunan, P. Ravindran, T. Rani, S. Mohan, Journal of Molecular Structure, Accepted (2010).

[73]. Zeroka D, Jensen J O, J. Mol. Struct.: Theochem., 425, 181 (1998).

[74]. Ong K K, Jensen J O, Hameka H F, J. Mol. Struct.: Theochem., 459,131(1999).

[75]. Jensen J O, Banerjee A, Merrow C N, Zeroka D, J.M. Lochner, J. Mol. Struct., Theochem., 531, 323 (2000).

[76]. Jensen J O, Zeroka D, J. Mol. Struct.: Theochem., 487, 267 (1999).

[77]. Hameka H F, Jensen J O, J. Mol. Struct.: Theochem., 331, 203 (1995)

[78]. Ellzy M W, Jensen J O, Hameka H F, Kay J G, Zeroka D, Spectrochim. Acta Part A, Vol.57A, 2417 (2001).

[79]. Lee S Y, Boo B H, Bull. Korean Chem. Soc., Vol.17, 760 (1996).
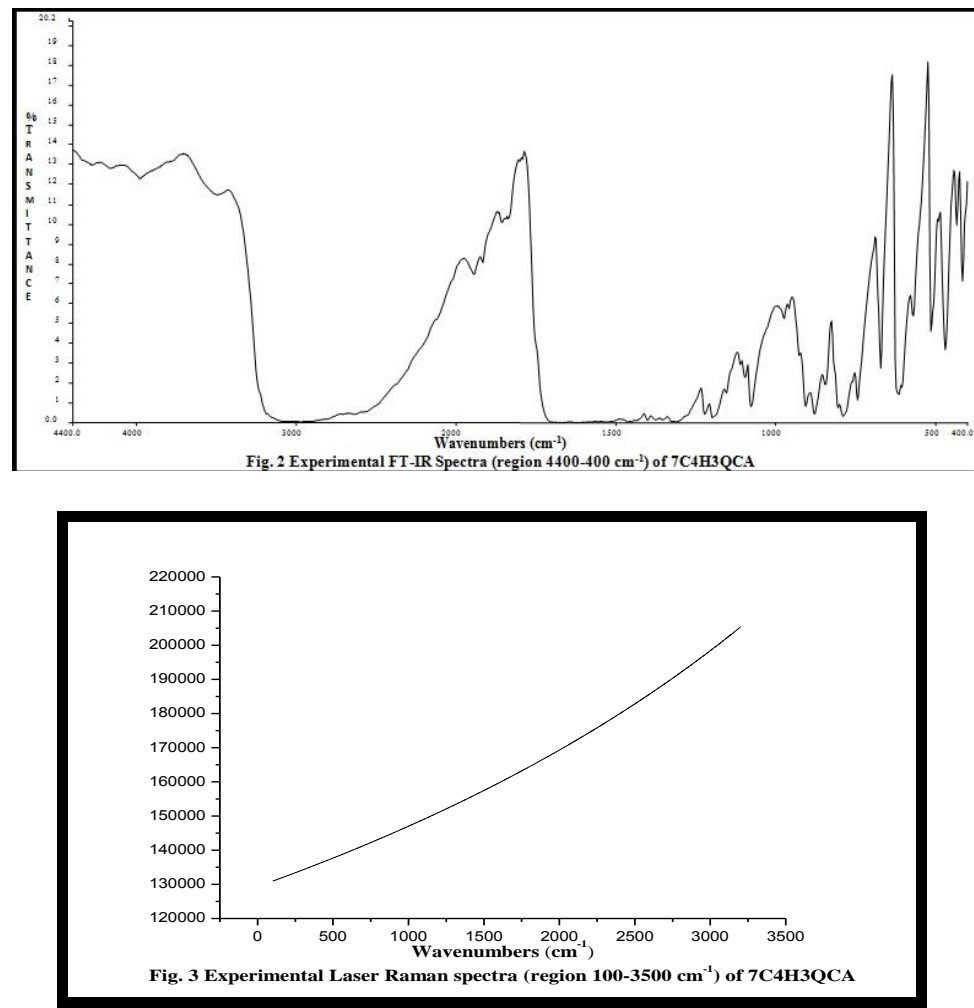


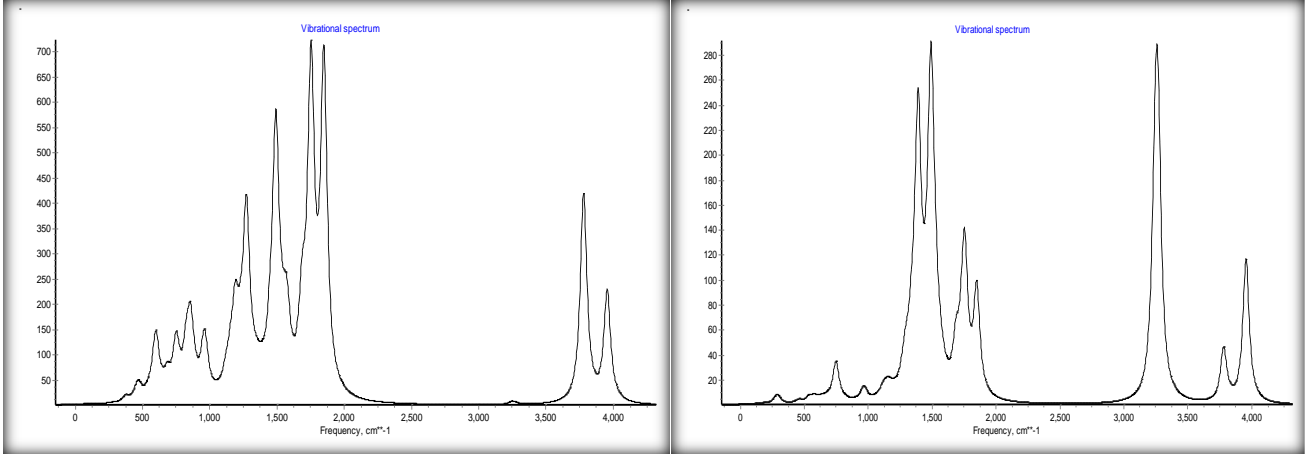

Fig. 4 Computed FT-IR and FT-Raman spectra of 7C4H3QCA HF/6-31+G (d, p)

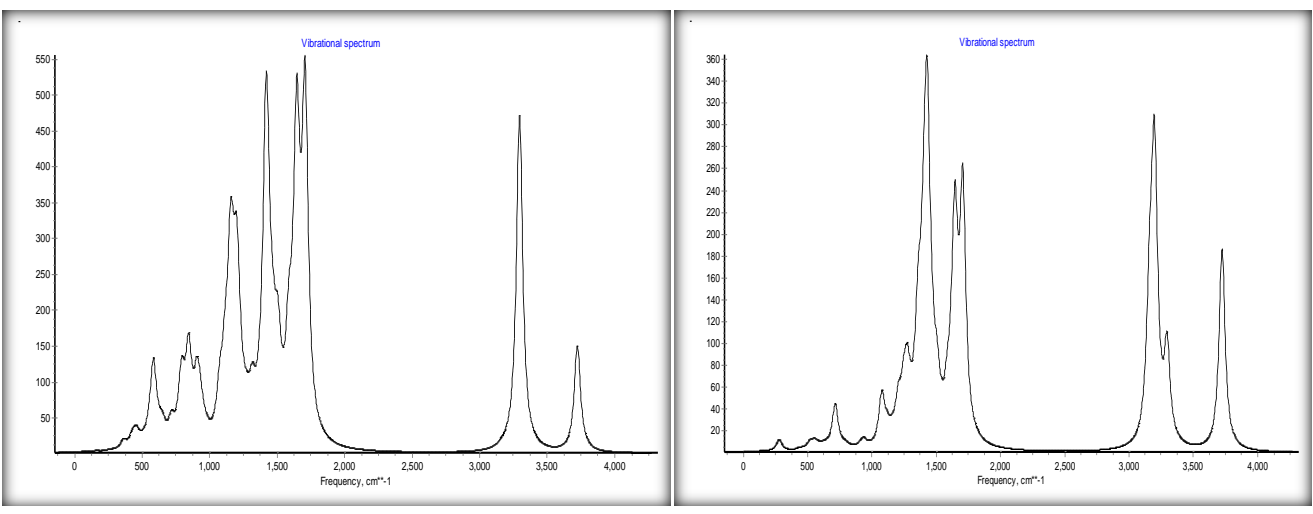

Fig. 5 Computed FT-IR and FT-Raman spectra of 7C4H3QCA B3LYP/631+G (d, p) 